\title{
COVID-19-Related Challenges in Dental Education: Experiences From Brazil, the USA, and Australia
}

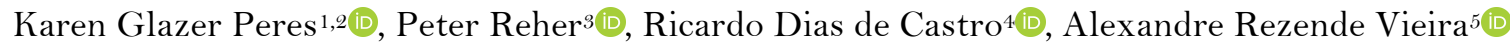

\begin{abstract}
${ }^{1}$ National Dental Research Institute Singapore, National Dental Centre Singapore, Singapore.
${ }^{2}$ Oral Health ACP, Health Services and Systems Research Programme Duke-NUS Medical School, Singapore.

${ }^{3}$ School of Dentistry and Oral Health, Griffith University, Gold Coast, Australia.

${ }^{4}$ Department of Clinical and Social Dentistry, Federal University of Paraiba, João Pessoa, PB, Brazil.

${ }^{5}$ Department of Oral Biology, University of Pittsburgh School of Dental Medicine, Pittsburgh, Pennsylvania, USA.
\end{abstract}

Author to whom correspondence should be addressed: Professor Karen Peres, National Dental Research Institute Singapore, National Dental Centre Singapore, Oral Health ACP, Health Services and Systems Research Programme, DukeNUS Medical School, 5 Second Hospital Ave, Singapore.168938. E-mail: karen.g.d.a.peres@ndcs.com.sg.

Academic Editor: Yuri Wanderley Cavalcanti

Received: 15 June 2020 / Accepted: 07 July 2020 / Published: 09 July 2020

How to cite this article: Peres KG, Reher P, Castro RD, Vieira AR. COVID-19-related challenges in dental education: experiences from Brazil, the USA, and Australia. Pesqui Bras Odontopediatria Clín Integr. 2020; 20(supp1):e0131. https://doi.org/10.1590/pboci.2020.130

\begin{abstract}
Objective: To describe and compare how three dental schools from different countries (Australia, Brazil, and the USA) have managed experiences in dental education during the COVID-19 crisis. Material and Methods: It is a descriptive study reporting the experience that three distinct dental schools faced during the COVID-19 pandemic. They represent countries that adopted different measures to tackle the pandemic and were undergoing different stages of the disease. Results: After the WHO declared the COVID-19 pandemic, the Federal University of Paraíba suspended all on-site teaching, research, and service activities. For the return to teaching activities, the use of information and communications technology resources for distance learning was recommended. At the School of Dental Medicine (University of Pittsburgh), all research activities were suspended or, otherwise, could not be interrupted because of the employment of unique materials or supplies. When the pandemic started, Australia was one of the first countries to introduce strong regulations related to social distancing, travel restrictions, testing and tracking of infected patients. As such, the universities started to be closed from mid-March, cancelling all clinical and preclinical activities, maintaining online theoretical activities, such as seminars, lectures, and journal clubs. Conclusion: Numerous and critical difficulties have arisen as a result of the pandemic for individuals, communities and institutions that will have long-lasting effects. Our students face disruption to their education and career; our professional colleagues will be challenged rebuilding their practices, while staff at all Dental Schools are experiencing various hardships.
\end{abstract}

Keywords: Coronavirus; SARS Virus; Education, Dental, Graduate; Educational Technology. 


\section{Introduction}

Coronaviruses $(\mathrm{CoV})$ are a specific type of group virus, which include ribonucleic acid (RNA) in its genetic material [1]. Their primary targets are epithelial cells of the respiratory and gastrointestinal tracts, which facilitates the transmission of the viral load through different ways such as fomites, airborne or faecaloral [2]. In early January 2020, the Chinese Center for Disease Control and Prevention [3] reported a novel coronavirus (SARS-COVID-2) as the causative agent of a human disease named COVID-19. Late January 2020, the World Health Organisation (WHO) declared a public health emergency of international concern, and a global pandemic later was announced, in March 2020 [4]. As of 4 June 2020, COVID-19 had affected 213 countries and territories around the world, translated in more than 6 million cases and almost 400 thousand deaths worldwide [5].

Nations have taken different measures to slow down the spread of the virus that causes COVID-19. Lockdown, shelter in place, stay at home orders, travel ban, and social distancing, for instance, were measures that dramatically impacted the globe both socially and economically. The physical distancing of one metre or more, wearing face masks for both health-care workers and the general public as well as eye protection, are mechanisms already supported by findings from a recent systematic review and meta-analysis [6].

One of the sectors hardest disrupted by the COVID -19 pandemic crisis was the area of health education. Dental education was affected significantly. Given the high degree of uncertainty about the natural history of the disease, and the need to protect the health of students, staff and patients, actions such as suspension of teaching, researching and other activities to campus were taken using a range of strategies, which varied across countries and the stage of the local epidemic curve. Moreover, practice preparation, such as the review of Personal Protective Equipment (PPE) protocols, the organisation of the pre and post clinical environment, and clinical dental procedures were discussed and implemented. Numerous and critical difficulties and challenges have arisen as a result of the measures adopted that will have lasting effects. Facing an unprecedented time in the dental education system worldwide, this is an excellent opportunity to share new experiences, learn and develop.

As of this writing in early June 2020, USA and Brazil ranked first and second in the number of confirmed cases worldwide, respectively [5]. In Australia, the number of new cases rapidly increased and peaked in March 2020. Since mid-April, there has been a sustained and relatively low number of new cases reported daily, with less than 20 new cases per day since 22 April [7]. This study aimed to describe and compare how three dental schools from different countries have managed experiences in dental education during the COVID-19 crisis. Australia, Brazil, and the USA have the pandemic spread at different times and magnitudes.

\section{Material and Methods}

This article is a descriptive study reporting the experience that three distinct dental schools faced during the COVID-19 pandemic. These schools have been chosen based on the authors' knowledge. They represent countries that adopted different measures to tackle the pandemic and were undergoing different stages of the disease at the time of writing this paper.

\section{Settings}

Brazil - Federal University of Paraíba, School of Dentistry 
Brazil is an upper-middle-income South American country, the fifth largest and the most populous nation globally, with a population of over 212 million [8]. It is the ninth economy in the world with 79th HDI position worldwide [9]. The number of Brazilian high education institutions surpasses 2,400, which includes 199 universities and 2,020 colleges; most of them (87.9\%) are private [10]. Only $16.5 \%$ of young adults aged $\geq$ 25 years have a tertiary education level. There are 542 dental schools in Brazil, of which 58 are public and free of tuition fees [11]. The Federal University of Paraíba (UFPB), in Joao Pessoa, Northeast Brazil (Figure 1), offers undergraduate and post-graduate degrees in the dental field and has approximately 400 students.

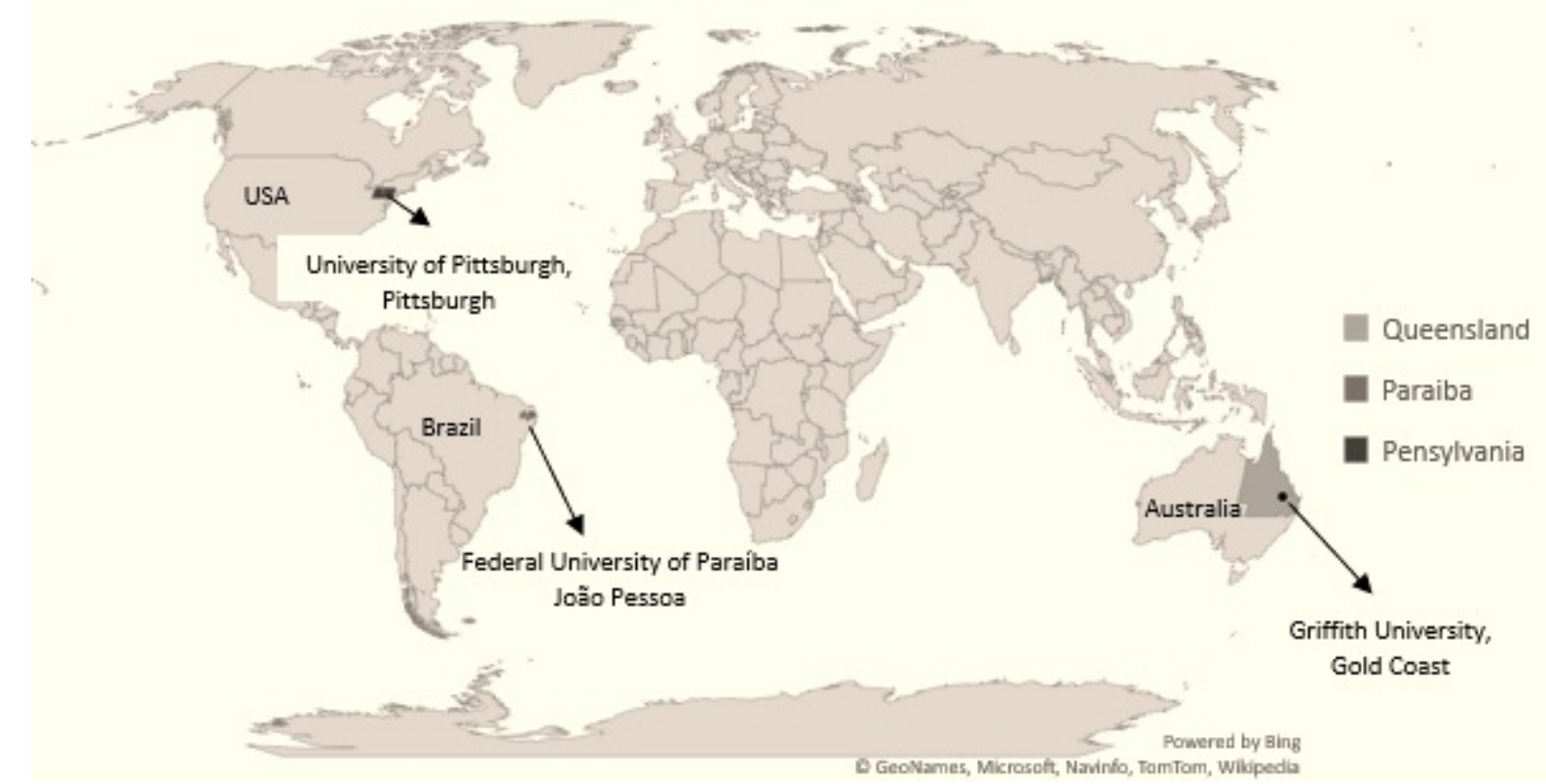

Figure 1. Location of dental schools-related to the study.

The USA - the University of Pittsburgh, School of Dental Medicine

Ranked as the global largest economy, the USA is located in central North America, with a population of over 300 million inhabitants [12]. The HDI index of 0.924 ranks the 13th global position [9]. Compared to most higher education systems around the world, the U.S. system is mostly independent of federal government regulation, and it is highly decentralized. The educational system receives funds from public and private sources, including tuition, federal and state funds, as well as endowments [13]. Dental education in the USA is a professional training after a college degree. Students must obtain a bachelor's degree at a university or college before applying to any of the 66 existing dental schools. The University of Pittsburgh is one of four educational institutions where training in dentistry is offered in the Pennsylvania North-eastern state (Figure 1). There are nearly 400 dental students enrolled.

\section{Australia - Griffith University, School of Dentistry and Oral Health}

Australia is the largest country in Oceania and the sixth-largest in the world, with a relatively small population of nearly 26 million [14]. The country is highly developed with the world's 14th largest economy, raking the third position according to the Human Develop Index (HDI) of 0.939 [9]. The education sector plays an essential role in the Australian economy, with 43 universities, out of which 40 are public. The Australian Government provides loans and subsidies to assist citizen students. Australia has 12 dental schools, 9 teaching Dentistry programs, and 3 teaching Oral Health Therapy. The School of Dentistry and Oral Health 
at Griffith University is located in Gold Coast, Queensland, east coast of Australia (Figure 1). The School has undergraduate degrees in Dentistry and Dental Technology, as well as post-graduate training programs in several disciplines, and research degrees such as MPhil and Ph.D. The School has approximately 600 dental students, with $20 \%$ being international students.

\section{Results}

Strategies in Dental Education During the COVID-19 Pandemic

The Federal University of Paraíba, School of Dentistry

After the WHO declared the COVID-19 pandemic, the Federal University of Paraíba suspended all on-site teaching, research, and service activities. For the return to teaching activities, the use of information and communications technology (ICTs) resources for distance learning was recommended, with the following considerations: 1) student access to the internet and computers; 2) training of teachers to use ICTs; 3) theoretical and practical nature of the curricular components. Remote teaching of theoretical curricular components was offered in all undergraduate programs; however, these were considered as a supplementary semester. Assessments were submitted online in a range of formats, such as quizzes, essays, and video production. When returning to face-to-face activities, considering that some students do not have a satisfactory socioeconomic condition that supports the use of ICTs, the online curricular components offered must be made available again in the face-to-face classrooms.

Immediately after suspension of face-to-face activities, a biosafety committee was formed, made up of academics and students of the dental school, to present a proposal to return to post-pandemic activities, including clinical care. A protocol for clinical care was elaborated considering safety measures recommended by Brazilian official health institutions [15], as well as scientific articles [16,17]. In general, the of personal protective equipment (PPE) such as masks N95 or PPF2, safety glasses, disposable caps and shoe covers, waterproof surgical apron, face shield, and procedure gloves were recommended, besides specificities detailed in Table 1.

The University of Pittsburgh, School of Dental Medicine

The response to the pandemic came slow, but when it happened, colleges and universities in the United States suspended classes for a week. Learning activities were shifted to virtual teaching in the followed week, using a combination of lecture recordings and live sections with faculty and students connected at the same time. At the School of Dental Medicine, all research activities were suspended (except for the projects that could be considered essential for the COVID-19 effort) or, otherwise, could not be interrupted because of the employment of unique materials or supplies. Services such as administrative meetings were moved to be $100 \%$ online. All elective patient care was postponed protecting staff and preserving PPE and patient care supplies. Urgent dental cases were discussed via teledentistry consultation until national guidelines were available from the Centers for Disease Control and Prevention [18]. These cases were seen within weeks when protocols for urgent care were nationally released (Table 1). 
Table 1. Restricted services and recommendations followed during the COVID-19 pandemic.

ADA Restrictions Covid-19
Services that can be Performed:
of high-speed handpieces, restorative procedures using high speed handpieces only provided with the use of rubber dam, non-surgical extractions, hand scaling (no use of ultrasonic scalers), medical management of soft tissue presentations (such as ulcers), TMD dysfunction management, denture procedures, preventative procedures such as the application of topical remineralising agents e.g. fluoride, orthodontic treatment.

Level 3 - Only dental treatments that do not generate aerosols, or where treatments generating aerosols is limited to: management of patients with acute dental pain e.g. endodontic treatment under rubber dam, or extraction, management of significantly damaged upper front teeth (e.g. due to trauma, with restorative treatment provided under rubber dam, soft tissue pathology e.g. ulcers, management of complex medically compromised patients with dental concerns which may compromise their systemic disease, management of those at a higher risk of rapid progression of dental disease due to socioeconomic or cultural factors,

be evaluated for body temperature.

- Definition of procedures for dressing and removing PPE in environments suitable for these purposes. To prevent cross-contaminations, dental care mus be provided in the proportion of one teacher for each pair of students, who will treat only one patient per day shift, thus enabling the disinfections of the clinical environment between appointments. This new routine must involve expanding the number of classes for each curricular component. During the dental treatment, in general, the following should be considered: 1) use of high-power suction systems to reduce the spread of aerosols to the environment; 2 ) preferential drying of the tooth / cavity mouthpiece with gauze or cotton, avoiding the use of the air jet of the triple syringe; 3) prioritization of chemicalmechanical surgical techniques, when possible; 4 preferential use, when possible, of absorbable suture threads; 5) use of extraoral radiographs, such as panoramic radiography or computer tomography,
Unlikely potential for patient harm: routine primary or specialty care. Large scale CT: if care cannot be delivered remotely, consider deferring until CT decreases. Utilize telehealth if appropriate. Minimal to moderate CT: if care cannot be delivered remotely, work towards expanding in person care as needed with priority for at risk populations and those whose care, if continually deferred, would

more likely result in patient harm. Utilize telehealth if appropriate. No to minimal CT: Resume regular care practices while continuing to utilize telehealth if appropriate. 
management of patients referred by a medical practitioner for medically necessary dental care

Level 4 - Only the following dental treatments are to be managed: swelling of the face, neck or mouth, dental trauma causing change in the position of teeth, soft tissue damage and/or significant pain, significant bleeding, difficulty opening the jaw and/or swallowing, referral from a specialist medical practitioner for assessment or management of a patient receiving urgent medical care for medically necessary dental care, dental pain causing loss of sleep, ulcers persisting for $3+$ weeks

Level 5 - No routine dental treatment provided. All patients with acute dental concerns to be directed to emergency care centres.

'Australia Dental Association. Dental Service Restrictions in COVID-19. Australian Dental Association, 25 March 2020. Available from: https://www.ada.org.au/Campaign/COVID-19/Managing-COVID19/Practice-Resources/Dental-restriction-Levels/ADA-dental-restriction-levels-in-COVID-19-Publishe.aspx. [Accessed on on June 8, 2020].

2Dental School of Federal University of Paraíba. Protocol of Biosafety of Dental School in Coping with COVID 19. 2020.

${ }^{3}$ Centers for Disease Control. Available from: https://www.cdc.gov/coronavirus/2019-ncov/hcp/framework-non-COVID-care.html. $\ulcorner$ Accessed on June, 11 2020 7 avoiding stimulation of salivation and coughing when taking intraoral radiography; 6) structural adequacy of the physical environment for clinical care. 
The forced period of isolation had an evident impact on dental students at the University of Pittsburgh. U.S. dental students are typically older than the corresponding students from Brazil. On average, they are four years older than Brazilian students, which causes a substantial financial investment in their education. The full dental course at the University of Pittsburgh costs US\$300,000 and, consequently, changes in how the learning was delivered to finish the semester due to COVID-19, created more anxiety. Online teaching was delivered with the offering of some additional contacts for guidance and emotional support. Besides teaching, other experiences such as research and service were profoundly affected as well.

\section{Griffith University, School of Dentistry and Oral Health}

When the pandemic started, Australia was one of the first countries to introduce strong regulations related to social distancing, travel restrictions, testing and tracking of infected patients. As such, the universities started to be closed from mid-March, cancelling all clinical and pre-clinical activities, maintaining online theoretical activities, such as seminars, lectures, and journal clubs. These activities required a steep learning curve by all students and academics, and platforms such as Microsoft Teams ${ }^{\circledR}$ and BlackBoard Collaborate ULTRA ${ }^{\circledR}$ became the main Learn \&Teaching tools used at Griffith University. Several clinically based scenarios were created and delivered in the format of online problem-based learning (PBL) discussions. All exams in Semester 1 were delivered online.

Throughout the pandemic, there was a strong collaboration between the main Dentistry regulatory bodies such as the Australian Dental Association (ADA), the Dental Board of Australia (DBA) and the Australian Council of Dental Schools (ACODS). A staged level of severity of restrictions was implemented by the ADA and endorsed by the other entities and supported by State and Federal Governments [19]. The restrictions ranged from level 1 to level 5, and staid on level 3 for March and April. This meant that only dental emergencies could be treated, including management of infections, pain, and bleeding, without aerosols (Table 1). During this time, the School created a minimal roster with clinical dentists and academics only, without students. From late-April, the government approved a reduction to ADA level 2 , and finally, at the end of May, it went down to level 1. Although these rules apply to all dentists in the country, the Dental schools have recently initiated their "return to clinic" strategy, and most are starting at level 2 restrictions [20].

\section{Discussion}

Back to "Normal" - How and When?

At the point of writing this paper (mid-June 2020), countries were facing different epidemic realities of the COVID-19 crisis. Brazil was close to the peak of its epidemic curve, the US was lowering the curve, and Australia had flattened it, reaching a level of the almost complete elimination of new cases. Therefore, it is interesting to compare how each country is planning and executing their return to "normal" clinical teaching in Dentistry.

\section{Brazil - Federal University of Paraiba, School of Dentistry}

The return to face-to-face activities, including pre-clinical and clinical teaching, is preceded by an extensive discussion and elaboration of protocols for the establishment of a new routine. The Brazilian Dental Education Association (ABENO) promotes a national debate. It proposes the creation of dental infection control or biosafety commission in each educational institution to carry out the diagnosis, infection control, and continuing education for all people involved. In public institutions, like the Federal University of Paraíba, 
the main challenges are related to the adequacy of the physical structure, availability of human resources, and acquisition of materials for the personal protection of teachers, students, and oral health technicians. The preparation of a strategic plan for the return to activities is expected, considering epidemiological indicators and occupancy rate of hospital beds for treatment of COVID 19

\section{The University of Pittsburgh, School of Dental Medicine}

After the end of the spring term (which runs from January through April), the summer term (AprilJuly) continued to offer classes online, and preparations were made for offering clinical experiences to the students who are in the treatment care phase of their training. The combinations of recorded clinical procedures and more in-depth discussions of clinical scenarios were offered to provide some experience to the students while all waited for authorization from the state regarding restabilising clinical activities. The physical layout of the dental clinics and pre-clinical laboratories was changed to minimize risks of COVID-19, allowing students to be at a safe distance from others while working. The plan is for resuming these activities within a month.

\section{Australia - Griffith University, School of Dentistry and Oral Health}

Discussions regarding how we should return to our pre-clinical and clinical activities started in April. From that point, it was already clear that regardless as to when we would return, key aspects would have to be observed, such as social distancing, review of infection control practices and specific COVID-19 assessment of patients and staff. In Australia, social distancing was determined as $1.5 \mathrm{~m}$, with no more than one person per 4 sqm of the room area. These basic principles meant that we had to do a very complex revision of our timetables and clinical sessions, as most classes would necessarily have to be "double taught". Most clinics had a 6-chair layout with one supervisor, and with the new model, we could only use three chairs, and the supervisor would look after two clinics. We had to reduce the length of the sessions from $3 \mathrm{~h}$ to $2 \mathrm{~h}$ and $30 \mathrm{~min}$, and by doing so we managed to have four sessions a day (from 7:30 am to 7:30 pm), instead of the regular three sessions per day. Although we could fit all students, overall, there was still an inevitable reduction of the number of patients seen per student, as we did not have enough physical space to double all sessions. This change in the timetable affected the entire school and required changes to the Prosthetics Lab as well as the Simulation Lab, ensuring we all followed this new timetable.

We are probably one of the first dental schools in the world to have started to have clinical activities with students. This was a staged approach, with Professional Dentists beginning on 25 May, PG students on 1 June, and UG students on 8 June. The reception area was redesigned, reduced to 1/3 of its capacity ensuring social distancing. A pre-entry checkpoint was created for all patients, staff and students before entering the clinic (temperature check, travel and COVID-19 history, hand sanitiser and band wrist identification). PPE has been reinforced, with the use of scrubs covered with disposable gowns, goggles, head nets and masks used at all times (N95 available). All patients and staff had to do a mouth wash (hydrogen peroxide) before treatment, and the use of rubber dam and high-volume suction were reinforced. The school started on ADA level 2; however, we are moving to level 1 from 15 June, following the same staged approach [19]. We are happy to report that so far, the clinical operation is working well. Patients are pleased to be back and appreciate the extra precautions implemented, and staff and students feel safe and engaged to be back on campus. 


\section{Conclusion}

Numerous and critical difficulties have arisen as a result of the pandemic for individuals, communities and institutions that will have long-lasting effects. Our students face disruption to their education and career; our professional colleagues will be challenged rebuilding their practices, while staff at all Dental Schools are experiencing various hardships. However, we believe that our response to these difficulties has been a challenging and rewarding learning experience. The way we practise dentistry and deliver dental education has changed significantly as a result of the COVID-19 pandemic, and we should share our experiences and learn from each other. We should take this scenario as an excellent opportunity for all of us to review our clinical practices, our biosafety, and be forever stimulated to try new ways to teach to the next generation of dentists. The future of dental education needs to incorporate the role of new pandemics within their accreditation requirements.

\section{Authors' Contributions}

KGP (D) 0000-0002-1730-2123 $\begin{aligned} & \text { Conceptualization, Formal Analysis, Writing - Original Draft Preparation and } \\ & \text { Writing - Review and Editing. }\end{aligned}$
$\begin{array}{lll}\text { PR } & \text { (D) } 0000-0002-4444-125 \mathrm{X} & \text { Methodology, Formal Analysis and Writing - Review and Editing. } \\ \text { RDC } & \text { (D) } 0000-0001-7986-7376 & \text { Methodology, Formal Analysis and Writing - Review and Editing. } \\ \text { ARV } & \text { (D) } 0000-0003-3392-6881 & \text { Methodology, Formal Analysis and Writing - Review and Editing. }\end{array}$
$\begin{array}{ll}\text { All authors declare that they contributed to critical review of intellectual content and approval of the final version to be } \\ \text { published. }\end{array}$

\section{Financial Support}

None.

\section{Conflict of Interest}

The authors declare no conflicts of interest.

\section{References}

[1] Woo PC, Huang Y, Lau SK, Yuen KY. Coronavirus genomics and bioinformatics analysis. Viruses 2010; 2(8):180420. https://doi.org/10.3390/v2081803

[2] Decaro N. Gammacoronavirus. In: Tidona CA, Darai G. The Springer Index of Viruses. London: Springer; 2011 , pp. 403-413.

[3] World Health Organization. Novel coronavirus - China. Geneva, Switzerland: World Health Organization. Available from: https://www.who.int/csr/ don/12-january-2020-novel-coronavirus-china/en/. [Accessed on June 12, 2020].

[4] World Health Organization (WHO). Coronavirus Disease (COVID-19) Pandemic. Geneva: WHO; 2019. Available from: https://www.who.int/emergencies/diseases/novel-coronavirus-2019. [Accessed on June 12, 2020].

[5] Johns Hopkins University \& Medicine. Coronavirus Resource Center. COVID-19 Dashboard by the Center for Systems Science and Engineering (CSSE) at Johns Hopkins University (JHU). Available from: https://coronavirus.jhu.edu/map.html. [Accessed on June 3, 2020].

[6] Chu DK, Akl EA, Duda S, Solo K, Yaacoub S, Schünemann HJ, et al. Physical distancing, face masks, and eye protection to prevent person-to-person transmission of SARS-CoV-2 and COVID-19: a systematic review and metaanalysis. Lancet 2020; 395(10292):1973-87. https://doi.org/10.1016/So 140-6736(20)31142-9

[7] Australian Government. Department of Health. Coronavirus (COVID-19) Health Alert. Coronavirus (COVID-19) Current Situation and Case Numbers. Available from: https://www.health.gov.au/news/health-alerts/novelcoronavirus-2019-ncov-health-alert/coronavirus-covid-19-current-situation-and-case-numbers. [Accessed on June 3, 2002].

[8] World Bank Group. Brazil. Available from: https://data.worldbank.org/country/brazil. [Accessed on June 5, 2020].

[9] Human Develop Report. Available from: http://hdr.undp.org/en/content/human-development-index-hdi. [Accessed on June 5, 2020].

[10] Brasil. Ministério da Educação. 2020. Cadastro Nacional de Cursos e Instituições de Educação Superior. Available from: http://emec.mec.gov.br/. [Accessed on June 7, 2020]. [In Portuguese] 
[11] Instituto Brasileiro de Geografia e Estatística. Pesquisa Nacional por Amostra de Domicílios Contínua. Educação 2018. 2019. Available from: https://biblioteca.ibge.gov.br/visualizacao/livros/liv101657_informativo.pdf. [Accessed on June 7, 2020]. [In Portuguese]

[12] United States Census Bureau. U.S. and World Population Clock. Available from: https://www.census.gov/popclock/. [Accessed on May 24, 2020].

[13] The Pew Charitable Trusts. Federal and State Funding of Higher Education. Available from: https://www.pewtrusts.org/en/research-and-analysis/issue-briefs/2015/06/federal-and-state-funding-of-highereducation. [Accessed on June 9, 2020].

[14] Australian Bureau Statistics. Australian Demographic Statistics, Dec 2019. Available from: https://www.abs.gov.au/AUSSTATS/abs@.nsf/mf/3101.0. [Accessed on June 5, 2010].

[15] Brasil. Ministério da Saúde. Painel Coronavirus. Available from: https://covid.saude.gov.br. [Accessed on June 7, 2020]. [In Portuguese]

[16] Peng X, Xu X, Li Y, Cheng L, Zhou X, Ren B. Transmission routes of 2019-nCoV and controls in dental practice. Int J Oral Sci 2020; 12:9. https://doi.org/10.1038/s41368-020-0075-9

[17] Lo Giudice R. The severe acute respiratory syndrome coronavirus-2 (SARS CoV-2) in dentistry. Management of biological risk in dental practice. Int $\mathrm{J}$ Environ Res Public Health 2020; 28:17(9):3067. https://doi.org/10.3390/ijerph 17093067

[18] Centers for Disease Control. Available from: https://www.cdc.gov/coronavirus/2019-ncov/hcp/framework-nonCOVID-care.html. [Accessed on June 11, 2020].

[19] Australia Dental Association. Available from: https://success.ada.org/ /media/CPS/Files/Open\%20Files/ADA_COVID19_Dental_Emergency_DDS.pdf?_ga=2. 253879752.110187285.1584496315-1622146531.1565271894. [Accessed on June 11, 2020].

[20] Australia Dental Association. Service Restrictions in COVID-19. Available from: https://www.ada.org.au/Campaign/COVID-19/Managing-COVID-19/Practice-Resources/Dental-restrictionLevels/ADA-dental-restriction-levels-in-COVID-19-Publishe.aspx. [Accessed on June 9, 2020]. 